\title{
Inside out: the role of nucleocytoplasmic transport in ALS and FTLD
}

\author{
Steven Boeynaems ${ }^{1,2}$ Elke Bogaert ${ }^{1,2}$ - Philip Van Damme ${ }^{1,2}$. \\ Ludo Van Den Bosch ${ }^{1,2,3}$
}

Received: 29 March 2016 / Revised: 27 May 2016 / Accepted: 28 May 2016 / Published online: 6 June 2016

(C) The Author(s) 2016. This article is published with open access at Springerlink.com

\begin{abstract}
Neurodegenerative diseases are characterized by the presence of protein inclusions with a different protein content depending on the type of disease. Amyotrophic lateral sclerosis (ALS) and frontotemporal lobar degeneration (FTLD) are no exceptions to this common theme. In most ALS and FTLD cases, the predominant pathological species are RNA-binding proteins. Interestingly, these proteins are both depleted from their normal nuclear localization and aggregated in the cytoplasm. This key pathological feature has suggested a potential dual mechanism with both nuclear loss of function and cytoplasmic gain of function being at play. Yet, why and how this pathological cascade is initiated in most patients, and especially sporadic cases, is currently unresolved. Recent breakthroughs in C 9 orf 72 ALS/FTLD disease models point at a pivotal role for the nuclear transport system in toxicity. To address whether defects in nuclear transport are indeed implicated in the
\end{abstract}

Electronic supplementary material The online version of this article (doi:10.1007/s00401-016-1586-5) contains supplementary material, which is available to authorized users.

Steven Boeynaems

steven.boeynaems@vib-kuleuven.be

Ludo Van Den Bosch

ludo.vandenbosch@vib-kuleuven.be

1 Department of Neurosciences, Experimental Neurology and Leuven Research Institute for Neuroscience and Disease (LIND), KU Leuven-University of Leuven, 3000 Leuven, Belgium

2 Laboratory of Neurobiology, Vesalius Research Center, VIB, Campus Gasthuisberg O\&N4, PB912, Herestraat 49, 3000 Leuven, Belgium

3 Department of Neurology, University Hospitals Leuven, 3000 Leuven, Belgium disease, we reviewed two decades of ALS/FTLD literature and combined this with bioinformatic analyses. We find that both RNA-binding proteins and nuclear transport factors are key players in ALS/FTLD pathology. Moreover, our analyses suggest that disturbances in nucleocytoplasmic transport play a crucial initiating role in the disease, by bridging both nuclear loss and cytoplasmic gain of functions. These findings highlight this process as a novel and promising therapeutic target for ALS and FTLD.

Keywords Neurodegeneration · Aggregation - TDP-43 . Nuclear transport $\cdot$ Nuclear pore $\cdot$ Importin $\cdot$ Exportin . Ran-GTP cycle

\section{Introduction}

Amyotrophic lateral sclerosis (ALS) and frontotemporal lobar degeneration (FTLD) are two devastating adult-onset neurodegenerative disorders. In ALS, motor neurons in the motor cortex, brainstem and spinal cord degenerate. This leads to motor problems, muscle weakness and paralysis. These motor impairments are progressive, and ALS is usually fatal within 3-5 years after diagnosis [114]. In FTLD, cortical neurons in the frontal and anteriotemporal cortex of the brain degenerate. FTLD patients can present with behavioral and/or personality changes or language problems [85]. In recent years, it has become increasingly clear that these seemingly unrelated diseases, ALS and FTLD, are the extremes of a disease spectrum. This idea originated from the clinical overlap in a number of patients presenting a mix of motor problems typical for ALS and behavioral changes characteristic of FTLD [114]. In the last decade, solid evidence has emerged for shared molecular mechanisms. Mutations in a set of genes can cause both diseases, 
and many ALS and FTLD patients share a similar pathology [68, 109].

For both ALS and FTLD, hereditary forms of the disease exist. In approximately $10 \%$ of ALS patients and in $40 \%$ of FTLD patients, the disease runs in the family. The neurodegeneration in these familial cases is caused by mutations in a heterogeneous set of genes (reviewed in Renton et al. [99]; Sieben et al. [109]). While the cause of the disease in sporadic cases is mostly unknown, the majority of patients present with similar neuropathological lesions: the RNA-binding protein TAR DNA-binding protein 43 (TDP43) was identified as the major component of the ubiquitinpositive neuronal inclusion bodies observed in nearly all ALS patients ( $97 \%)$ and patients of the FTLD-TDP subtype $(\sim 45 \%)[3,68,90]$. The significance of this finding was consolidated by the subsequent discovery of mutations in the TAR DNA-binding protein gene (TARDBP), encoding TDP-43, in approximately $4 \%$ of familial ALS patients $[49,99,111]$ and rare FTLD cases [9]. This discovery has set the stage for a prime role for TDP-43 aggregation in ALS/FTLD pathogenesis. Besides TDP-43, another RNAbinding protein was found to be strongly implicated in the disease: mutations in fused in sarcoma (FUS) are found in $\sim 5 \%$ of ALS cases and rare cases of FTLD [60, 99, 123], and wild-type FUS protein aggregates are present in about $10 \%$ of FTLD patients [89]. Moreover, patients carrying hexanucleotide repeat expansions in the chromosome 9 open reading frame 72 gene (C9orf72), the most common genetic cause of ALS-FTLD [25, 100], have repeat RNA foci which sequester numerous RNA-binding proteins [20, 38, 64, 81]. Additionally, these patients also have dipeptide repeat peptides which interfere with RNA metabolism [61], and TDP-43 pathology [52]. These breakthroughs from the last decade have caused a paradigm shift in the ALS/FTLD field. The disease is no longer exclusively considered as a proteinopathy - a mere defect in protein folding — but is increasingly appreciated as a problem in ribostasis, or the conjoined misregulation of RNA-binding proteins and their responsive RNAs [98]. Despite these novel insights, the exact cause of the pathological aggregation of these RNAbinding proteins and their consequences remain elusive.

\section{RNA-binding proteins are strongly implicated in the pathology and genetics of ALS/FTLD}

To obtain a comprehensive view on protein misregulation in ALS and FTLD, we performed a systematic search of studies reporting protein mislocalization and/or aggregation in post-mortem patient material. PubMed search terms included 'ALS', 'MND', 'FTLD', 'FTD', 'pathology', 'aggregation', 'aggregate', 'inclusion' and 'mislocalization' (last search on 26/01/2016). Proteins were identified
Fig. 1 RNA-binding proteins are strongly implicated in ALS/ FTLD pathology. a Schematic overview of protein mislocalization and aggregation in ALS/FTLD, as determined in post-mortem brain or spinal cord (muscle for MSP data). Patients are divided into different categories based on their pathology: SOD1, TDP-43, FUS, mutant FUS, Tau or DPR. DPR pathology is concurrent with RNA foci and TDP pathology. ALS/FTLD disease genes are boxed. Proteins can be grouped according to their function: 'RNA metabolism', 'Nuclear transport', 'Cytoskeleton' and 'Proteostasis'. Misregulated RNA-binding proteins can be further divided into three classes based on their misregulation: I (red), II (orange) and III (yellow). Asterisk denotes debated findings; hash denotes occurrence in several neurodegenerative diseases; double hash denotes occurrence in all protein aggregation diseases. $A D$ Alzheimer's disease, $H D$ Huntington's disease, $M S P$ multisystem proteinopathy, $S C A 2$ spinocerebellar ataxia type 2, $a M N D$ atypical motor neuron disease. b Network analysis using GeneMANIA indicates that all pathological proteins are highly interactive. Physical interactions are depicted in red, genetic in green, and colocalization in blue. Ubiquitin was not included in this network. c Word cloud depicting significantly overrepresented terms, as analyzed by ingenuity pathway analysis (IPA). Functional terms are green, disease and pathology terms black. Terms are scaled to the $-\log 10$ ( $p$ value). References: TDP-43 [86], FUS [52, 87, 117], EWS [21, 87], TAF15 [22, 87], Matrin-3 [47], hnRNPA1 [42, 53, 88], hnRNPA2B1 [53], hnRNPA3 [81], TIA-1 [35, 70, 124], RBM45 [19], HuR [77], NONO [108], SMN [44, 122], PDCD7 [44], Coilin [44], Gemin-8 [122], PABP-1 [35, 75], ATX2 [29, 31], G3BP-1 [124], TTP [124], eIF3b [70], rpS6 [35], eIF4g [28], Drosha [96], XRN1 [125], Staufen-1 [125], C9orf72 [52, 133], Nup62 [58, 84], Nup88 [58], Nup107 [144], Nup153 [58], Nup205 [144], Importin $\alpha-1$ [92], Importin $\beta-1$ [58, 84], Transportin-1 [91], Ran [126], Rangap-1 [133, 144], Tau [109, 137], NF-H [52, 131], $\beta$-actin [131], Peripherin [52, 131], KAP-3 [116], TTBK1 [66], TTBK2 [66], RGNEF [52], SOD1 [52, 128], Optineurin [16], RNF19A [41], Ubiquilin-2 [12], p62 [52], ubiquitin [101], PDI [6] and unc-119 [74]

as misregulated when they were found aggregated in inclusion bodies or were mislocalized, based on immunohistochemistry or immunofluorescence in brain or spinal cord (muscle in multisystem proteinopathy patients). The results are graphically presented in Fig. 1a and show that at least 53 proteins are misregulated in patients $[6,12,16$, $19,21,22,28,29,31,35,41,42,44,47,52,53,58,66$, $70,74,75,77,81,84,86-88,91,92,96,101,108,116$, $117,122,124-126,128,131,137]$. This set of pathological proteins could be divided into four main groups based on functional annotations derived from UniProt and the literature. 'RNA binding proteins' constitute about $50 \%$ of this list, highlighting their key role in the disease. The remaining proteins were involved in 'Cytoskeleton', 'Proteostasis' or 'Nuclear transport'. While the first three categories are widely appreciated as important players in the disease [102], 'Nuclear transport' has received limited attention [26]. Using GeneMANIA software [127] and data from a recent large-scale interactomics study [39], we constructed an interaction network for the 53 identified misregulated proteins. Despite the large heterogeneity of the input set, the network included all proteins (Fig. 1b). This suggests that despite their different functions, they act together in 
a
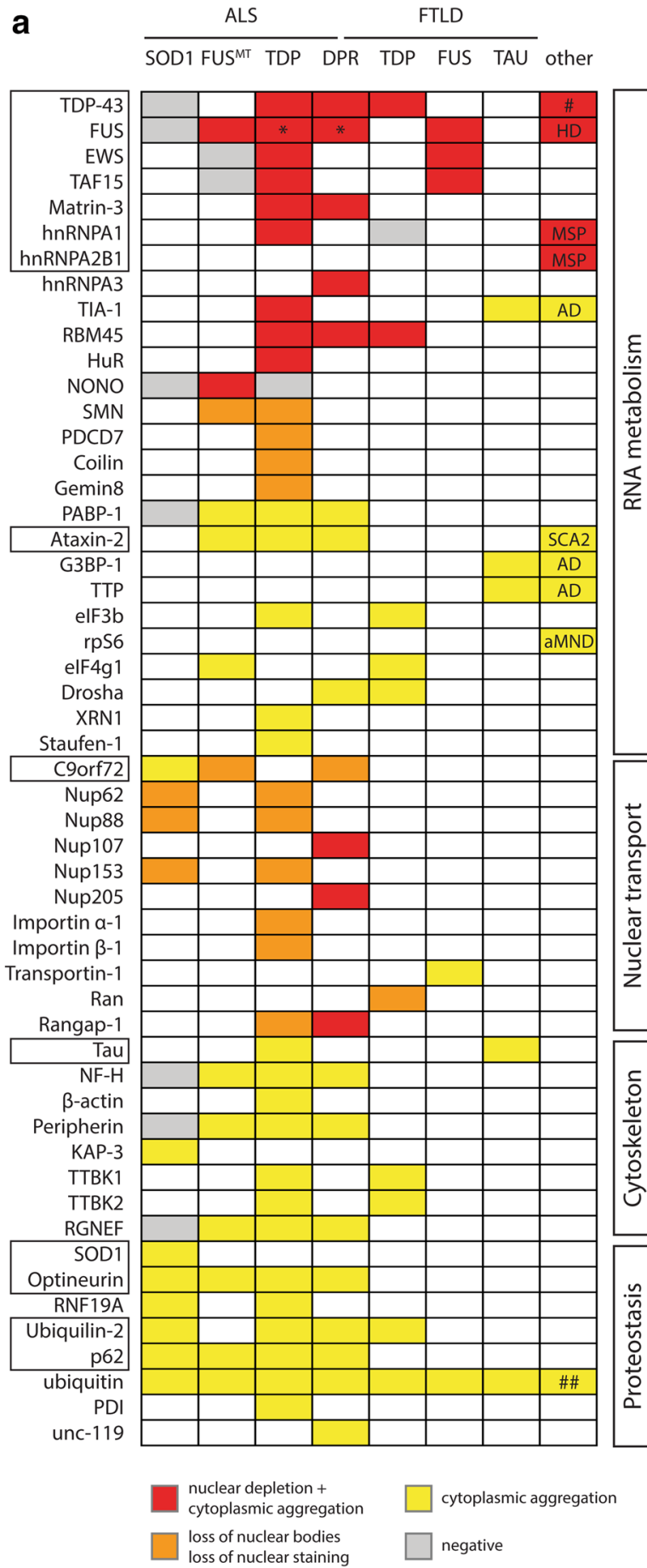

b

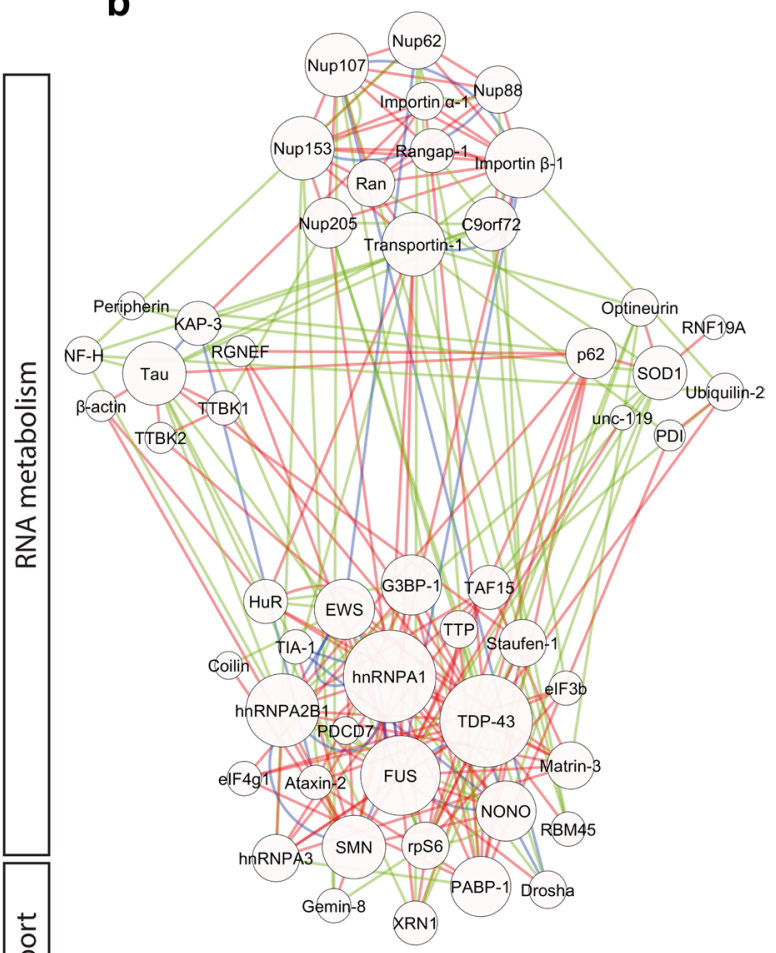

C

accumulation of neurofilaments assembly of splicing of RNA Parkinson's disease

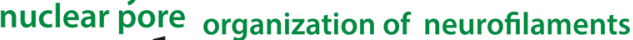
motor neuron size of
axons processing of RNA Alzheimer's disease axonal transport inclusion body myopathy Paget's disease of bone frontotemporal dementia gliosis microtubule dynamics translation import of protein $\begin{gathered}\text { expression } \\ \text { of RNA }\end{gathered}$ of protein metabolism response aggregation of mitochondria of protein accumulation of RNA axonogenesis formation of transport of ANA
inclusion bodies common pathways. To identify these pathways, we performed enrichment analysis on the pathology protein set using Ingenuity Pathway Analysis (IPA ${ }^{\circledR}$, QIAGEN, http:// www.qiagen.com/ingenuity). Disease terms significantly enriched included 'motor neuron disease' and 'frontotemporal dementia', which can be expected given the origin of the input data set (Fig. 1c, Supplementary Data). Also, 'Paget's disease of bone' and 'inclusion body myopathy' were found. This is also not surprising as it has become increasingly clear in the last few years that both these diseases share several pathological hallmarks and disease genes with ALS and FTLD [13, 118]. Consequently, all of these diseases are often classified as multisystem proteinopathies [118]. Pathology-related terms included 'formation of inclusion bodies' and other previously implicated abnormalities, such as 'accumulation of neurofilaments' [134] and 'accumulation of mitochondria' [73]. Functional terms included 'translation of protein' and 'processing of 
RNA', but also 'transport of protein' and 'transport of RNA' along with 'axonal transport'. Indeed, the transport of ribonucleoprotein particles along the axon for local synaptic translation has become a prime pathological mechanism in ALS [2, 69], hereby bridging the gap between the earlier implicated cytoskeletal defects and the new interest in RNA metabolism.

We performed the same analysis for genes linked to ALS [99] and/or FTLD [109], and we found similar results (Fig. S1, Supplementary Data). This suggests that the identified actors and pathways, especially centering on RNA metabolism, are indeed implicated in the pathogenesis of these diseases.

\section{Dissecting RNA-binding protein pathology: what can we learn?}

From the pathological and genetic findings, RNA-binding proteins emerge as a major class of actors in disease. Understanding the consequences but especially the cause of their misregulation could, hence, provide us with invaluable clues on the pathogenesis of ALS and FTLD.

We classified the implicated RNA-binding proteins in three major classes (see Fig. 1a) on the basis of their described pathological alterations. Firstly, proteins which under normal conditions mainly localize to the nucleus, but in the context of the disease mislocalize to the cytoplasm and aggregate (class I, red). Secondly, proteins which show a decreased number of nuclear bodies in disease (class II, orange). Thirdly, cytoplasmic proteins which also target the inclusion bodies seen in patients (class III, yellow).

Twelve of the affected RNA-binding proteins fall into class I. They include TDP-43 and FUS themselves, but also other related RNA-binding proteins which are mutated in rare familial cases, i.e., TATA-binding protein-associated factor 2N (TAF15) [22], EWS RNA-binding protein 1 (EWS) [21], Matrin-3 [47], and heterogeneous nuclear ribonucleoproteins A1 (hnRNPA1) [53] and A2B1 (hnRNPA2B1) [53]. Under normal conditions, these proteins are predominantly localized in the nucleus, where they serve essential functions in transcription and RNA processing. Hence, their nuclear depletion suggests a nuclear loss-offunction disease mechanism, besides the potential cytoplasmic gain of function associated with the inclusion bodies. Noteworthy in this regard are the different knockout and knockdown models generated which present with ALS-related phenotypes [43, 136] and gross transcriptome abnormalities [63]. Proteins in class II are as well depleted from their normal nuclear localization, hence, also suggesting a loss of function [44, 122]. Despite the nuclear predominance of class I proteins, they shuttle to the cytoplasm in a tightly regulated manner, where they control RNA transport, stability, decay and translation [62]. Interestingly, upon cellular stress, several of these RNA-binding proteins accumulate in large cytoplasmic ribonucleoprotein complexes called stress granules [7], and the formation of these stress granules is an essential step in the stress response. Proteins in class III are also known to localize to stress granules [7]. Given the strong similarities in protein content with the disease aggregates, stress granules have been suggested as potential stepping stones toward inclusion body formation [98]. Pathological aggregation hence could also perturb normal cytoplasmic function of these RNA-binding proteins or lead to a novel toxic gain of function.

Extensive efforts have been made to resolve the issue whether disease is caused by nuclear loss of function or cytoplasmic gain of function of the RNA-binding proteins. The available evidence so far suggests that both events are not mutually exclusive and could play an equally important role in the disease [68]. Identifying the pathways upstream of both cytoplasmic mislocalization and aggregation is of pivotal importance, as it could uncover targets for therapeutic intervention that prevent both nuclear loss-of-function and cytoplasmic gain-of-function mechanisms.

\section{Nuclear transport: bridge between loss and gain of function?}

Given the nuclear depletion of several RNA-binding proteins in patients, impaired nuclear import has previously been suggested as a pathogenic mechanism, and moreover, as a key initiating event in pathogenesis [26]. Indeed, most pathogenic FUS mutations affect its nuclear localization sequence (NLS) and interfere with its proper nuclear targeting [28]. Compellingly, the nuclear/cytoplasmic ratio of different FUS mutants in vitro is inversely correlated with the age of disease onset in FUS-ALS patients [28]. In addition to alterations in its amino acid sequence, methylation of the FUS NLS also perturbs its nuclear targeting [27]. No NLS mutants for TDP-43 have been described in ALS or FTLD patients up to now. However, caspase-3 cleavage and alternative splicing in patients are known to generate an aggregation-prone C-terminal fragment, which lacks a functional NLS and, hence, is invisible for the nuclear transport machinery [135, 146].

Most mutations in TDP-43 [26], TAF15 [22], EWS [21], hnRNPA1 [53], hnRNPA2B1 [53] and several in FUS [26], specifically target their prion-like domains. These domains are disordered and contain amyloidogenic zipper motifs capable of inducing $\beta$-sheet formation and aggregation, similar to yeast prions [57]. Disease-causing mutations often target key conserved residues in these zippers [21, 22, 53], making these proteins more aggregation-prone. Once formed, aggregates of either mutant or wild-type 


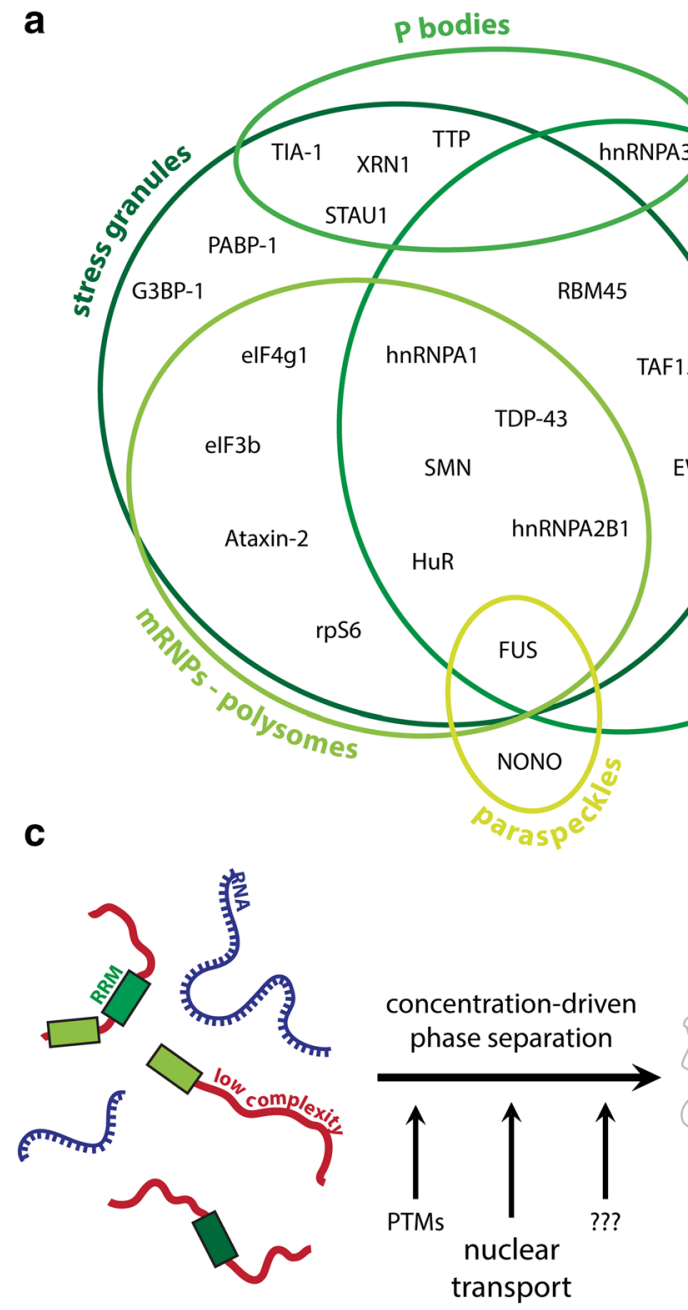

a

Fig. 2 ALS/FTLD-related RNA-binding proteins undergo liquidliquid phase transitions. a All RNA-binding proteins misregulated in ALS/FTLD are part of endogenous membrane-less organelles. b Several of these RNA-binding proteins are part of stress granules in vivo [7] or precipitate with $\beta$-isox in vitro [51] (green illustrates percent of total). c Scheme depicting RNA-binding protein phase transitions and the role of nuclear transport in this process. These phase transi-

RNA-binding proteins are able to seed prion-like aggregation of the remaining soluble pool. As these proteins shuttle constantly from nucleus to cytoplasm, such sequestration will trap these proteins in cytoplasmic aggregates and lead to a subsequent nuclear depletion.

As mentioned above, cytoplasmic inclusion bodies have been proposed to arise from stress granules [26, 98]: more than $70 \%$ of the pathological RNA-binding proteins that we identified are known stress granule components (Fig. 2a, b) [7]. This suggests that inclusion bodies could be seeded by stress granules or could arise from their improper clearance. Autophagy was shown to play a major role in this clearance, and interestingly, ALS/FTLD causing b
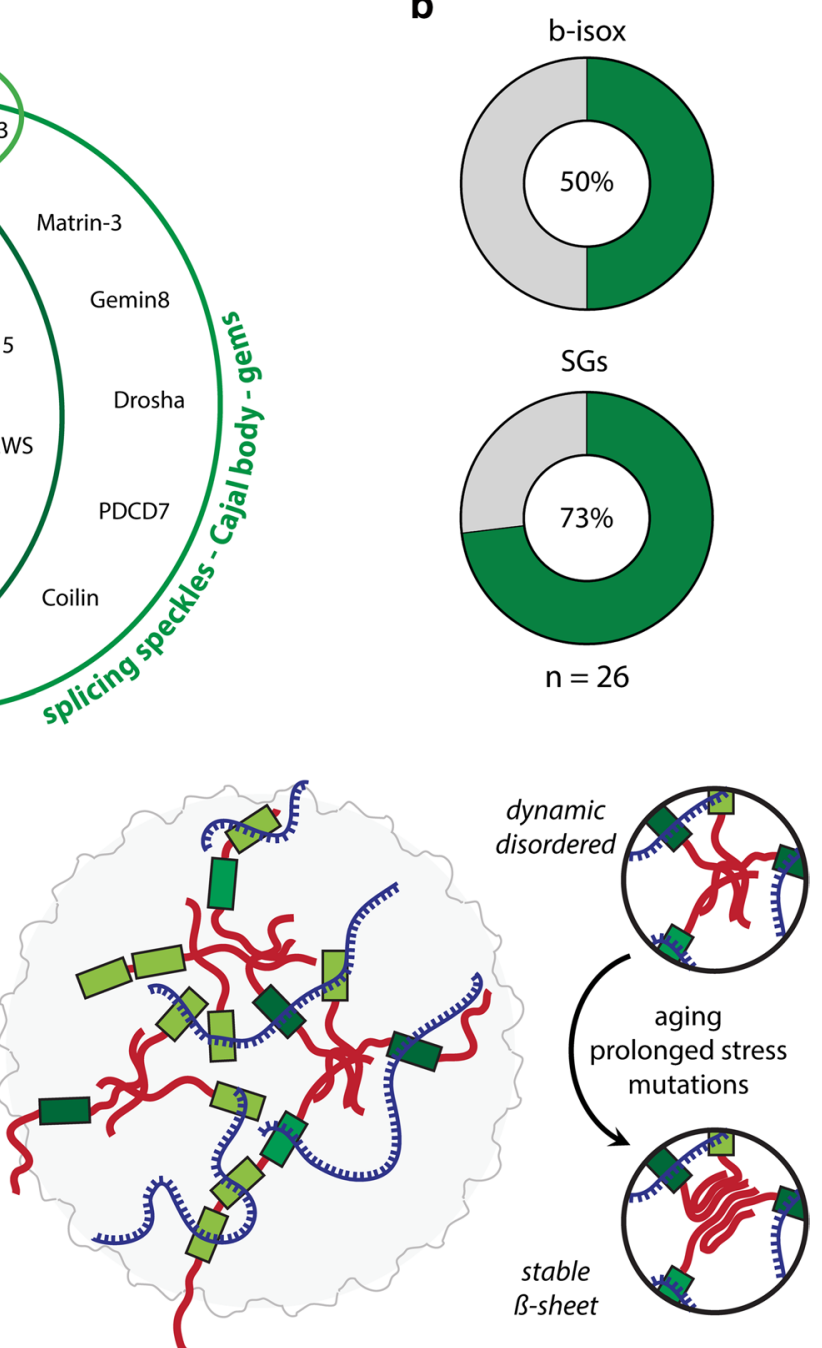

tions strongly depend on the local concentrations of the involved RNA-binding proteins. Disaggregases, such as VCP, and post-translational modifications (PTMs) also play a role in this process. Due to defects in the proper regulation of this process, e.g., aging and disease mutations, liquid-like stress granules can probably seed pathological aggregation

mutations in the autophagy protein valosin-containing protein (VCP) indeed perturb stress granule dissolution [13]. Recently, it was discovered that stress granules form by a process called phase transition. Similar to for example water, which can condense from vapor to fluid and freeze from fluid to solid, ALS- and FTLD- related RNA-binding proteins (e.g., TDP-43, hnRNPs and FUS) can undergo a similar phenomenon in vitro and in cell culture $[15,79,83$, 94] (Fig. 2c). Depending on specific in vitro conditions, such as concentration, salt and temperature, several RNAbinding proteins spontaneously demix from a watery solution and form liquid-like protein droplets. These droplets are highly reminiscent of cellular stress granules. Although 
disease-related mutations did not affect this liquid-like state, they promoted excessive $\beta$-sheet aggregation and transformed liquid droplets into solid aggregates [79, 83, 94]. As was the case for droplet formation, this maturation process was also strongly dependent on protein concentration. Partial maturation of the fluid-like interactions into more stable $\beta$-sheet structures seems to be inherent to stress granules in vivo $[46,132]$. This illustrates the necessity of a tight control of stress granule dynamics to avoid excessive pathological aggregation.

Given the strong concentration dependence of stress granule dynamics, nucleocytoplasmic transport seems to be important in regulating this process. Indeed, inhibiting nuclear import of hnRNPs spontaneously induces the induction of stress granules [79]. On the other hand, overexpressing FUS NLS mutants [28] or removing the NLS sequences from TDP-43 [146] has similar effects. This shows that raising the cytoplasmic concentrations of these RNA-binding proteins is sufficient to induce stress granule formation. With respect to this, it is interesting to note that these proteins occur at endogenous intracellular concentrations which induce droplet formation in vitro (e.g., $[\mathrm{hnRNPA} 1]_{\text {cell }}=7.64 \mu \mathrm{M}[39]>[\mathrm{hnRNPA} 1]_{\text {droplet }}=0.5$ $\mu \mathrm{M}$ [79]). This implies that cells must have evolved effective ways to regulate the initiation of such liquid-like phase transitions, more specifically, by controlling local concentrations through subcellular compartmentalization. Indeed, these proteins seem to withstand spontaneous phase separation at high concentrations in the nucleus for reasons currently unknown.

Nuclear transport factors themselves, such as importins and Ran, are well-established stress granule components $[34,72]$ and are known to regulate stress granule dynamics $[17,34,138]$. This suggests that these processes are indeed tightly linked and co-regulated. Of note, both FUS and TDP-43 control their cellular concentrations by means of autoregulation. High nuclear levels will result in a degradation of their own mRNAs through binding of the $3^{\prime} \mathrm{UTR}$ sequences [14, 147]. Pathogenic $3^{\prime} \mathrm{UTR}$ mutations which interfere with this process have been reported for both FUS and TDP-43 [36, 147]. This results in their overexpression which promotes aggregation. This crucial autoregulatory pathway once more stresses the need for proper nuclear import/export in the control of FUS and TDP-43 function.

Other membrane-less cellular compartments, e.g., the nucleolus or P granules, are also controlled by concentration-dependent phase transitions [10, 11]. Compellingly, all pathological RNA-binding proteins are found in such organelles (Fig. 2a), suggesting that this process is of major importance to the function of these RNA-binding proteins both in health and disease. For example, while a defect in nuclear import of class I proteins results in their cytoplasmic aggregation, a similar defect could underlie loss of nuclear bodies for class II proteins. In this case, lowered nuclear levels would lead to the dissolution of their nuclear bodies.

Nucleocytoplasmic transport bridges nuclear depletion and cytoplasmic aggregation, the two major pathological findings in ALS and FTLD. Besides this, nuclear transport factors are an important class of pathological proteins (Fig. 1a). Furthermore, mutations in FUS affect binding to its corresponding importin [28], and conversely, wildtype FUS inclusions sequester this specific importin [91]. All together, these findings advocate for a pivotal role of nucleocytoplasmic transport in the pathogenesis of ALS and FTLD.

\section{Nuclear transport factors are modifiers of ALS/ FTLD disease models}

We reviewed the literature on different ALS/FTLD models and their modifiers to find out whether there is support for a role for nucleocytoplasmic transport in the disease. Many research groups have harnessed the power of yeast and fly genetics to perform high-throughput genetic screens. Figure S2a gives an overview of the screens performed in ALS/FTLD models.

Fly ALS models of TDP-43, FUS and VAMP-associated protein B (VAPB) toxicity were used to identify genetic modifiers [24, 45, 142]. These modifiers included nuclear transport factors (Fig. S2a). Likewise, yeast genetic modifier screens for TDP-43 and FUS toxicity yielded modifiers in this process as well $[4,54,113]$ (Fig. S2b). Despite the involvement of nuclear transport factors in these disease models, convincing evidence for a modifying role of these proteins has come from a recent work on C9orf72. Repeat expansions in the non-coding part of this gene result in the generation repeat RNAs [64, 129], which are translated by an ATG-independent mechanism into five dipeptide repeats (DPRs) [5, 80, 82, 148]. To investigate the underlying mechanisms of $C 9$ orf72 ALS-FTLD, a genome-wide modifier screen in flies expressing an expanded GGGGCC repeat has been performed [32]. This led to the identification of numerous nuclear transport factors which were able to suppress or enhance the repeat RNA-induced rough eye phenotype [32] (Fig. S2a). Flies expressing the repeat expansion showed a defective nuclear mRNA export, which was reproduced in cortical neurons derived from induced pluripotent stem cells from C9orf72 patients. As the model used in this study can display effects originating from both RNA and DPR toxicity, it remains unclear which of them causes the defects in nuclear transport. However, it has been suggested that in the current fly models with moderate repeat sizes, DPRs are the predominant mediators of neurodegeneration [78, 121]. 
The generation of codon-optimized ATG-dependent DPR expression constructs has allowed our laboratory and others to investigate protein toxicity independent from RNA toxicity in C9orf72. Expression of proline-arginine or glycine-arginine DPRs was toxic in yeast and induced rough eye phenotypes in fly [8, 48, 78, 121, 129]. Two genome-wide yeast screens [48] and a screen targeting nuclear transport in fly [8] uncovered similar modifier genes, which also showed partial overlap with the modifiers from the GGGGCC screen (Fig. S2a). These findings suggest an important role of DPRs in the nucleocytoplasmic transport defects observed in these models. Another recent study concludes that direct RNA toxicity is involved in these defects as well, through an aberrant interaction of GGGGCC RNA with Ran GTPase-activating protein 1 (RanGAP1) [144], a key regulator of the energy gradient driving nucleocytoplasmic transport (Fig. S2a). Interestingly, RanGAP1 was also found trapped in GA aggregates in mouse brain [145]. Lastly, the C9orf72 loss-of-function hypothesis, due to lowered transcription levels, has not yet been ruled out. Recent reports suggest that the protein itself could operate in autophagy [105] and stress granule assembly [71], but also in nucleocytoplasmic transport [133].

All these suggested mechanisms in C9orf72 pathogenesis are not mutually exclusive, and future work is required to untangle their relative contributions to the disease (reviewed in [37]). However, all of them seem to point toward nucleocytoplasmic transport as a key player in $C 9$ orf72 pathogenesis, confirming the previously anticipated role for this process in ALS and FTLD [26].

\section{Nuclear transport defects are implicated in ALS and FTLD}

The recent developments in the C9orf72 field point at key pathways in nucleocytoplasmic transport. These findings could explain the mislocalization and aggregation of TDP43 and other RNA-binding proteins in patients carrying a repeat expansion. Yet, why wild-type proteins mislocalize in other types of the disease, and especially in sporadic patients, remains largely enigmatic.

ALS and FTLD are typically adult-onset disorders, suggesting that aging and its related processes are crucial to induce the disease. Interestingly, the efficiency and selectivity of nucleocytoplasmic transport deteriorates significantly during aging [23]. This can be largely attributed to the fact that several nuclear pore proteins are among the most long-lived proteins in post-mitotic neurons [103]. Postmitotic cells are unable to repair damaged nuclear pores, which become leaky during aging. Oxidative stress, a well-known hallmark of aging and implicated in several neurodegenerative disorders [65], is known to cause such damage to the nuclear pore [23, 140], but also to other components of the nuclear transport machinery [18, 59]. Several nuclear transport factors themselves have already been found misregulated in post-mortem ALS and FTLD patient material [58, 84, 92, 126, 144] (Fig. 1a). However, the precise reason for this mislocalization has remained elusive. A recent landmark study concludes that defects in proteostasis could be involved in this process [130]. It was found that cytoplasmic aggregation of synthetic amyloidogenic proteins, as well as disease relevant proteins, such as TDP-43 fragments, did cause mislocalization and aggregation of nuclear pore subunits and other nuclear transport factors. This resulted in defects in protein import and also in mRNA export. Interestingly, mice expressing mutant superoxide dismutase 1 (SOD1) showed misregulation of different nuclear pore components and import factors [143]. Additionally, aggregates of mutant VAPB [120] or TDP-43 [107] also affected the solubility of these proteins (Fig. S2b). Of note, wild-type VAPB itself seems to be important in nuclear pore assembly [120]. Lastly, wild-type FUS aggregates sequester transportin-1 and coaggregate with other cargoes in FTLD-FUS cases [91].

Besides protein aggregation, defects in RNA metabolism are considered to be a cornerstone of ALS/FTLD pathogenesis [68]. TDP-43 itself regulates numerous nuclear transport genes [106, 126]. Consequently, TDP-43 deregulation could initiate a positive feedback loop by perturbing nuclear transport. TDP-43 knockdown in cell lines led to depletion and mislocalization of several nuclear transport factors [112] (Fig. S2b). Also, TDP-43 mislocalized in an FTLD mouse model, and this was accompanied by nuclear depletion of Ran GTPase (Ran) [126]. TDP-43 was shown to regulate Ran expression, and loss of TDP-43 function resulted in lower Ran levels. Moreover, overexpression of Ran was able to rescue neurodegeneration and TDP43 mislocalization in cortical neurons derived from this mouse model [126]. This latter finding, together with the recent $C 9$ orf72 reports [32, 48, 144], suggests that nucleocytoplasmic transport could be an interesting therapeutic strategy.

Despite the importance of nuclear transport proteins in the pathology of ALS/FTLD, this group of genes has not been strongly implicated in the genetics of the disease so far. A notable exception is GLE1 RNA export mediator (Gle1). Mutations in Gle1 were recently linked to ALS cases [50]. Glel knockdown did induce motor neuron defects in embryonic zebrafish, which could be rescued by wild type but not by mutant Gle1. Besides functioning in mRNA export, Gle1 has been also shown to regulate as well stress granule dynamics [1]. This genetic link of ALS with an established mRNA export factor once more illustrates the potential importance of this process in the disease. As indicated before, the C9orf72 protein is also 
a

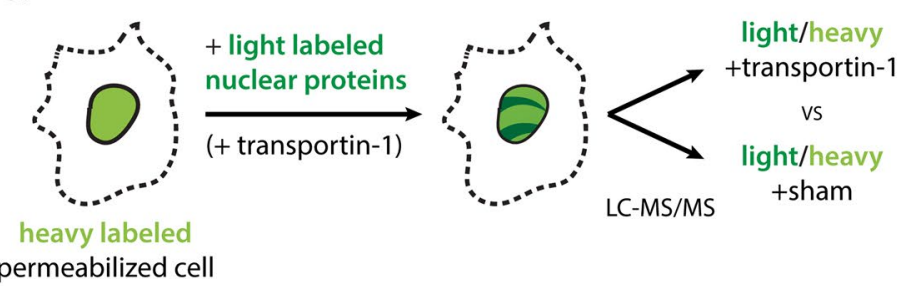

C

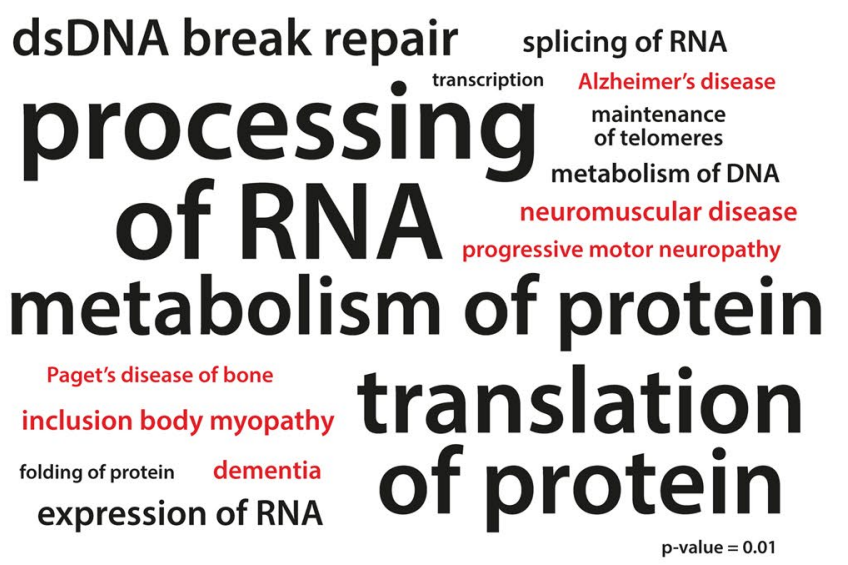

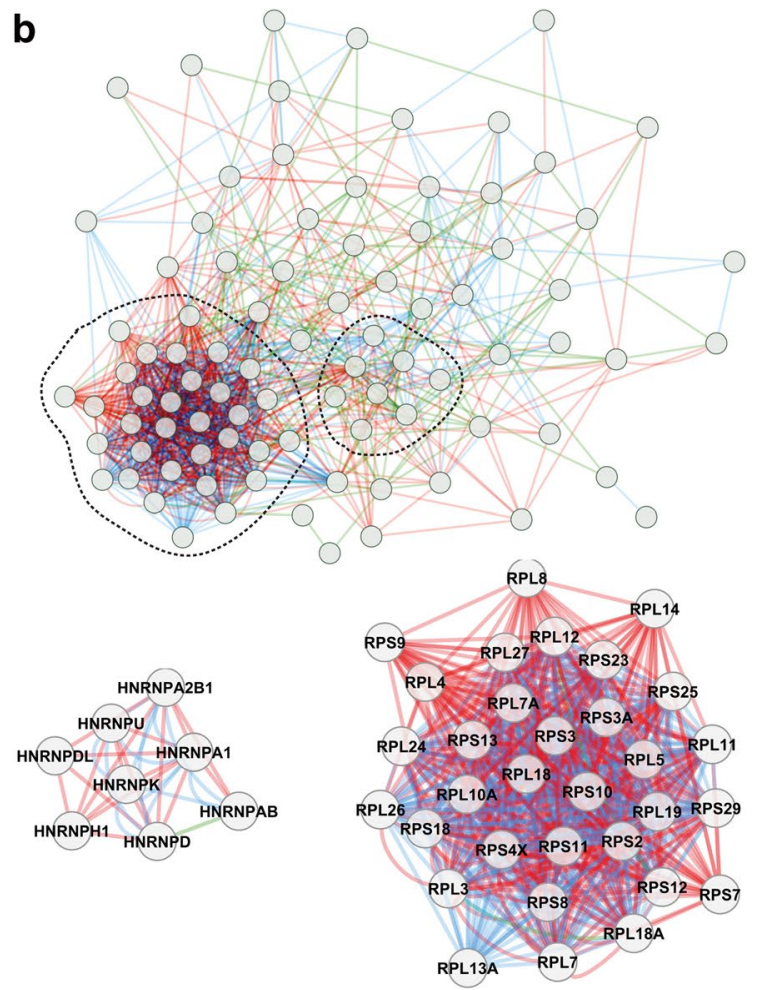

Fig. 3 Nuclear transport cargoes are strongly implicated in ALS/ FTLD and related pathways. We analyzed transportin-1 and exportin-1 cargo lists, which were experimentally validated. a Scheme of experimental setup for determining transportin-1 cargoes [55]. b These cargo proteins form a dense interaction network. Two subnet-

a suspected nuclear transport factor [133], which could further increase the genetic evidence for a role of nuclear transport in the disease.

\section{Can nuclear transport defects initiate disease?}

Nucleocytoplasmic transport involves protein import and export, mediated by importins and exportins, respectively. Numerous different import and export factors exist, but the most important ones include transportin-1, the importin $\alpha 2$ / $\beta 1$ complex and exportin-1. Interestingly, these different import factors were recently identified in different genetic screens for modifiers of C9orf72 toxicity [8, 32, 48, 144], as discussed above. Using quantitative mass spectrometry in combination with in vitro import assays, two studies aimed to identify cargoes dependent on transportin- 1 or importin $\alpha 2 / \beta 1$ for their nuclear targeting (Fig. 3a) [55, 56]. In each case, about 80 high-confidence cargoes were found using stringent cut-off criteria. We used these proteins to reconstruct interaction networks for both import pathway clients. Figure $3 b$ shows the highly interactive network of transportin-1 cargoes, suggesting that all these proteins works, the ribosome and hnRNP family, are highlighted. Red depicts physical interactions, green genetic, and blue colocalization. $\mathbf{c}$ Word cloud of significantly overrepresented terms, as analyzed by ingenuity pathway analysis (IPA). Functional terms are black, and disease terms red. Terms are scaled to the $-\log 10$ ( $p$ value)

share similar functions. Two subnetworks drew our interest: firstly, ribosomal proteins are one of the main clients of nuclear import, since after cytoplasmic translation, these proteins need to shuttle back to the nucleolus for ribosomal subunit assembly. Of note, nucleolar stress and a defective ribosomal biogenesis have been recently implicated in ALS/FTLD models [38, 48, 61, 115, 129]. Secondly, several hnRNP family members were also detected among the transportin-1 cargoes. This family of RNA-binding proteins has been increasingly implicated in ALS/FTLD in the last years $[42,81]$, and mutations in some of them are rare causes of the disease [53]. Enrichment analysis uncovered strong associations with ALS/FTLD-related pathways for the entire cargo set. Significantly enriched terms especially centered on RNA metabolism and protein translation (Fig. 3c, Supplementary Data). Moreover, when looking at enriched disease terms, we found that these sets of proteins were associated with 'neuromuscular disease' and 'dementia'. Also, the related proteinopathies 'Paget's disease of bone' and 'inclusion body myopathy' resulted from this analysis. Network and enrichment analysis of the importin $\alpha 2 / \beta 1$ dataset gave similar results as for transportin-1 (Supplementary Data). 
Nuclear export mediated by exportin-1 can be specifically inhibited by leptomycin B [119]. Using quantitative mass spectrometry, proteins affected in their subcellular distribution by this compound have been identified [119]. Whereas most proteins were unaffected, just over 100 proteins showed a significant depletion from the cytoplasm and/or accumulation in the nucleus. When analyzing this set for enriched functional and disease terms, similar pathways were found as for the importin cargo sets (Supplementary Data). Interestingly, nuclear transport factors themselves were also misregulated by leptomycin B treatment. Indeed, nucleocytoplasmic transport is dependent on the continuous translocation of different effectors back and forth in and out of the nucleus to maintain their appropriate cellular distribution, e.g., importins need to go back to the cytoplasm for binding new NLS cargoes. Hence, disrupting one aspect of this process will have widespread effects on both import and export.

Our analyses of nuclear transport cargo sets illustrate that problems in nucleocytoplasmic transport will affect processes implicated in the disease, especially centering on RNA metabolism. Moreover, the fact that these cargo sets show a strong enrichment for proteins already implicated in ALS/FTLD and related disorders, suggests that defects in nuclear transport could initiate important pathogenic cascades.

\section{Why are neurons vulnerable for nuclear transport defects?}

Nucleocytoplasmic transport is an essential process in cellular organization and functioning. So, if defects in nuclear transport are a cause of ALS/FTLD, why is degeneration largely restricted to specific neuronal populations? Explaining this discrepancy between general pathogenic pathways and selective cell death has been puzzling the neurodegeneration field for years, and applies to numerous established disease mechanisms, e.g., excitotoxicity, mitochondrial damage or protein aggregation [104].

A potential reason why nucleocytoplasmic transport defects could especially harm neurons can be found in their extreme cellular organization: neurons are the longest cells in the human body, e.g., motor neurons can reach lengths of up to $1 \mathrm{~m}$ in adults. This means that the synapse, the site of action, is located on a phenomenal distance from the nucleus. Synapses are, for their proper functioning, dependent on local translation and, hence, RNA transport along the axon. Numerous ALS/FTLD-associated genes are implicated exactly in this process [2,69]. Also, nuclear transport factors themselves are found locally in the axon and at the axon terminals where they play a crucial role in this long-distance communication [95, 141]. As discussed above, the post-mitotic nature of neurons predisposes them as well to age-related disturbances in nucleocytoplasmic transport [23, 103].

On the other hand, the central nervous system is a hot spot for alternative splicing events [97, 139]. Brain alternative splicing events are also more conserved during evolution than in other tissues [76], illustrating the importance of this process in normal brain functioning [97]. Such tissuespecific splicing events seem to fine-tune protein-protein interaction networks according to the specific need of the cell type [30]. Both ALS- and/or FTLD-linked genes and pathological proteins were significantly enriched for splicing factors ('splicing of RNA'; Benjamini-Hochberg corrected $p$ value $=1.21 \mathrm{E}-03$ and $1.84 \mathrm{E}-03$ ). Defects in splicing are also a common theme in neurological diseases [67]. Maintaining proper nuclear levels of splicing factors, hence, is key to neuronal functioning.

\section{Conclusions}

Landmark discoveries in the last decade have vastly expanded our knowledge on ALS and FTLD. The involvement of RNA-binding proteins has moved the field from viewing the diseases as exclusive proteinopathies to a more holistic view of ALS/FTLD as a problem in ribostasis, linking RNA-binding protein aggregation to problems in RNA metabolism. Mutations in numerous genes encoding such proteins strengthened this hypothesis, and finally, the discovery of the C9orf72 expansion consolidated the importance of RNA metabolism in the disease. However, key issues remain to be addressed. Especially, the exact underpinnings of RNA-binding protein mislocalization proved elusive. NLS mutations were identified in FUS, but why wild-type proteins mislocalize was unknown. Only very recently, the identification of nuclear transport genes as modifiers of $C 9$ orf 72 disease models shifted the focus of the field explicitly to nucleocytoplasmic transport.

In this review, we tried to discuss all data currently available on the role of nucleocytoplasmic transport in ALS and FTLD. Moreover, we tried to address the question whether transport defects could be an initiating event in the disease. We used meta-analyses and bioinformatics to investigate this option. We found that nucleocytoplasmic transport cargoes are indeed associated with ALS/FTLD and related pathogenic processes. This suggests that a disruption of their proper localization could result in a loss of their normal functions, such as RNA splicing and transport, both vital in neuronal health. The function of RNA-binding proteins is strictly regulated, and largely depends on their subcellular localization. High levels of specific RNA-binding proteins in the cytoplasm will initiate spontaneous compartmentalization of these proteins into fluid-like granules, 


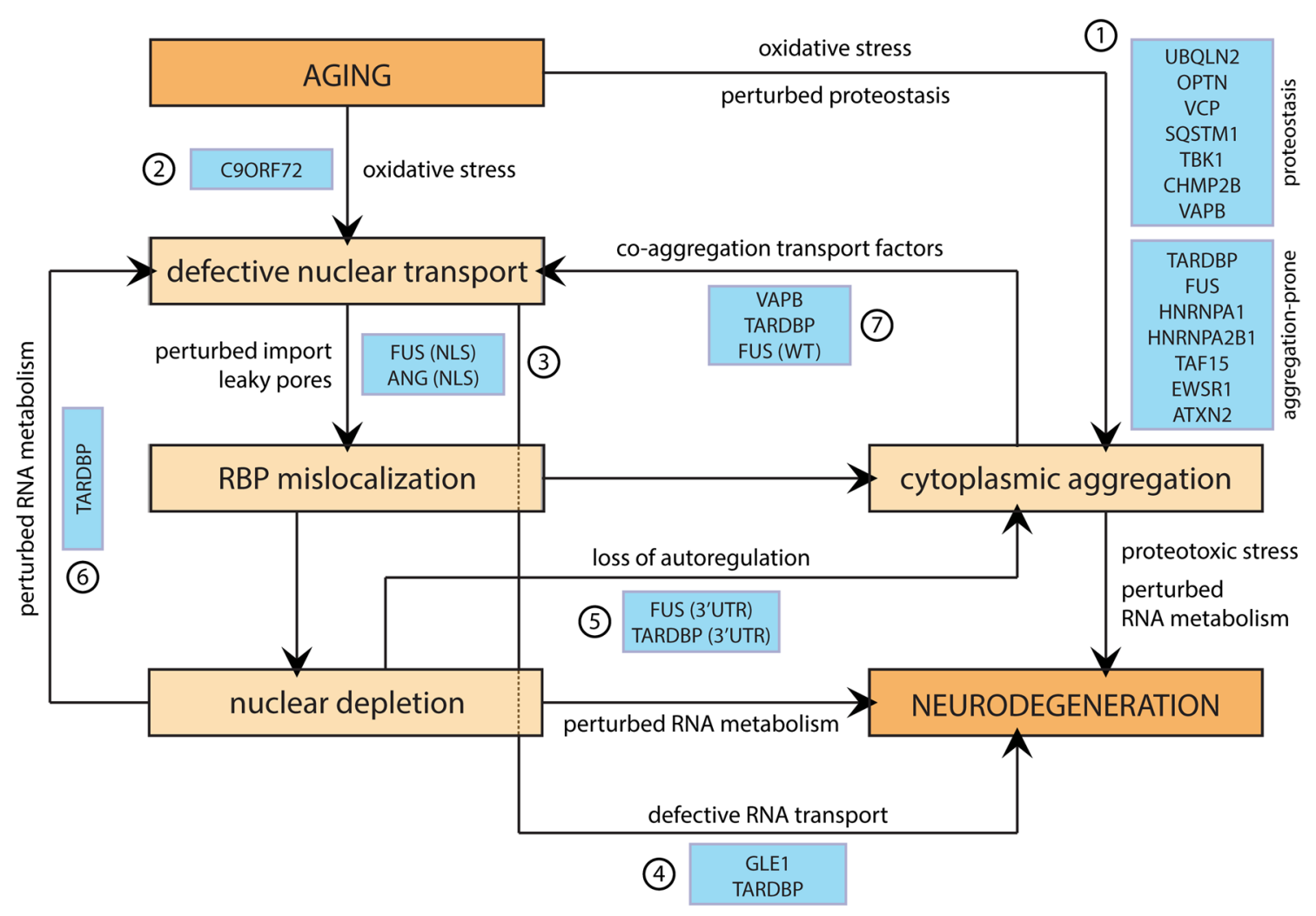

Fig. 4 Roadmap to neuronal death in ALS/FTLD. Hypothetical scheme showing occurrence of different pathogenic events in RNAbinding protein-related ALS/FTLD. Orange boxes depict natural processes associated with aging. Blue boxes show where disease mutants enhance pathological pathways. See Supplementary Data for disease gene functions. 1 Numerous disease mutations make RNA-binding proteins more aggregation-prone or affect proteins involved in proteostasis $[68,98]$. 2 C9orf72 repeat expansions induce nucleocytoplasmic transport defects $[8,32,48,144] .3$ NLS mutants of both FUS

such as stress granules. These dynamic organelles are the prime suspects as seeds of the pathological aggregates. Compellingly, more than $70 \%$ of all RNA-binding proteins misregulated in ALS/FTLD are known constituents of these stress granules. Recent evidence indeed suggests that RNAbinding proteins can undergo in vitro and in vivo concentration-dependent phase separations, and in vitro droplet maturation to pathological aggregates was observed in real time $[79,94]$. These data highlight the need for a tight control of stress granule dynamics, with an important role for nuclear transport in this process. Hence, both loss of normal nuclear function and cytoplasmic aggregation of RNAbinding proteins seem to converge on nucleocytoplasmic transport. In Fig. 4, we provide an overview of how nuclear transport could fit in the framework of ALS/FTLD pathogenesis, and how disease mutants affect these processes.

The recent $C 9$ orf 72 modifier studies provided us with a list of interesting candidates which could be more broadly implicated in ALS and FTLD. Figuring out whether and
[28] and Angiogenin (encoded by $A N G$ ) [93] have been reported, interfering with their proper nuclear targeting. 4 Mutations in GLE1 perturb RNA export [50], and mutant TDP-43 granules show altered axonal transport [2]. $53^{\prime}$ UTR mutants of FUS [147] and TDP-43 [14] interfere with their autoregulation resulting in overexpression of these proteins. 6 TDP-43 is an important genetic regulator of nuclear transport $[106,126] .7$ Various protein aggregates are known to sequester transport factors $[91,120,130]$

how nucleocytoplasmic transport could be perturbed in sporadic patients will be one of the key future challenges. Nucleocytoplasmic transport has been therapeutically targeted before, but mostly by inhibition [40]. More fundamental research into the precise regulation of this process will be needed to find ways to boost, specifically, the affected nucleocytoplasmic transport pathways. Indeed, upregulation of this process has been shown to rescue neurodegeneration in yeast, fly and neuronal ALS/FTLD models [48, 126, 144]. Consequently, nucleocytoplasmic transport could become a novel and promising therapeutic target for ALS and FTLD.

Acknowledgments The authors would like to thank Dr. A. D. Gitler, Dr. J. P. Taylor and Dr. F. B. Gao for valuable comments which significantly improved this manuscript. S.B. acknowledges A.v.d.W. for proofreading of the manuscript and helpful suggestions. The author's research is funded by the KU Leuven, the 'Opening the Future' Fund (KU Leuven), VIB, the Research Foundation Flanders (FWO-Vlaanderen), the Agency for Innovation by Science and Technology (IWT, 
Project MinE and iPSCAF), the Interuniversity Attraction Poles Programme P7/16 initiated by the Belgian Science Policy Office, the Belgian Alzheimer Association (SAO-FRA), the FWO-Vlaanderen under the frame of E-RARE-2, the ERA-Net for Research on Rare Diseases (PYRAMID), a EU Joint Programme-Neurodegenerative Disease Research (JPND) project (STRENGTH and project RiMod-FTD), NIH (NS079183), the Association Belge contre les Maladies neuroMusculaires (ABMM), the Muscular Dystrophy Association (MDA), and the ALS Liga Belgium. S.B. received a PhD fellowship from the Agency for Innovation by Science and Technology (IWT). E.B. holds a post-doctoral fellowship and P.V.D. a senior clinical investigatorship from FWO-Vlaanderen.

Open Access This article is distributed under the terms of the Creative Commons Attribution 4.0 International License (http://creativecommons.org/licenses/by/4.0/), which permits unrestricted use, distribution, and reproduction in any medium, provided you give appropriate credit to the original author(s) and the source, provide a link to the Creative Commons license, and indicate if changes were made.

\section{References}

1. Aditi Folkmann AW, Wente SR (2015) Cytoplasmic hGle1A regulates stress granules by modulation of translation. Mol Biol Cell 26:1476-1490. doi:10.1091/mbc.E14-11-1523

2. Alami NH, Smith RB, Carrasco MA, Williams LA, Winborn CS, Han SSW et al (2014) Axonal transport of TDP-43 mRNA granules is impaired by ALS-causing mutations. Neuron 81:536-543. doi:10.1016/j.neuron.2013.12.018

3. Arai T, Hasegawa M, Akiyama H, Ikeda K, Nonaka T, Mori H et al (2006) TDP-43 is a component of ubiquitin-positive taunegative inclusions in frontotemporal lobar degeneration and amyotrophic lateral sclerosis. Biochem Bioph Res Co 351:602611. doi:10.1016/j.bbrc.2006.10.093

4. Armakola M, Higgins MJ, Figley MD, Barmada SJ, Scarborough EA, Diaz Z et al (2012) Inhibition of RNA lariat debranching enzyme suppresses TDP-43 toxicity in ALS disease models. Nat Genet 44:1302-1309. doi:10.1038/Ng.2434

5. Ash PE, Bieniek KF, Gendron TF, Caulfield T, Lin WL, Dejesus-Hernandez M et al (2013) Unconventional translation of C9ORF72 GGGGCC expansion generates insoluble polypeptides specific to c9FTD/ALS. Neuron 77:639-646. doi:10.1016/j.neuron.2013.02.004

6. Atkin JD, Farg MA, Walker AK, McLean C, Tomas D, Horne MK (2008) Endoplasmic reticulum stress and induction of the unfolded protein response in human sporadic amyotrophic lateral sclerosis. Neurobiol Dis 30:400-407. doi:10.1016/j.nbd.2008.02.009

7. Aulas A, Vande Velde C (2015) Alterations in stress granule dynamics driven by TDP-43 and FUS: a link to pathological inclusions in ALS? Front Cell Neurosci. doi:10.3339/ Fncel.2015.00423

8. Boeynaems S, Bogaert E, Michiels E, Gijselinck I, Sieben A, Jovicic A et al (2016) Drosophila screen connects nuclear transport genes to DPR pathology in c9ALS/FTD. Sci Rep 6:20877. doi:10.1038/srep20877

9. Borroni B, Bonvicini C, Alberici A, Buratti E, Agosti C, Archetti $S$ et al (2009) Mutation within TARDBP leads to frontotemporal dementia without motor neuron disease. Hum Mutat 30:E974-E983. doi:10.1002/humu.21100

10. Brangwynne CP, Eckmann CR, Courson DS, Rybarska A, Hoege C, Gharakhani J et al (2009) Germline P granules are liquid droplets that localize by controlled dissolution/condensation. Science 324:1729-1732. doi:10.1126/science. 1172046
11. Brangwynne CP, Mitchison TJ, Hyman AA (2011) Active liquid-like behavior of nucleoli determines their size and shape in Xenopus laevis oocytes. Proc Natl Acad Sci USA 108:43344339. doi:10.1073/pnas.1017150108

12. Brettschneider J, Van Deerlin VM, Robinson JL, Kwong L, Lee EB, Ali YO et al (2012) Pattern of ubiquilin pathology in ALS and FTLD indicates presence of C9ORF72 hexanucleotide expansion. Acta Neuropathol 123:825-839. doi:10.1007/s00401-012-0970-z

13. Buchan JR, Kolaitis RM, Taylor JP, Parker R (2013) Eukaryotic stress granules are cleared by autophagy and Cdc48/VCP function. Cell 153:1461-1474. doi:10.1016/j.cell.2013.05.037

14. Budini M, Buratti E (2011) TDP-43 autoregulation: implications for disease. J Mol Neurosci 45:473-479. doi:10.1007/ s12031-011-9573-8

15. Burke KA, Janke AM, Rhine CL, Fawzi NL (2015) Residueby-residue view of in vitro FUS granules that bind the C-terminal domain of RNA polymerase II. Mol Cell 60:231-241. doi:10.1016/j.molcel.2015.09.006

16. Bury JJ, Highley JR, Cooper-Knock J, Goodall EF, Higginbottom A, McDermott CJ et al (2015) Oligogenic inheritance of optineurin (OPTN) and C9ORF72 mutations in ALS highlights localisation of OPTN in the TDP-43-negative inclusions of C9ORF72-ALS. Neuropathology. doi:10.1111/neup.12240

17. Chang WL, Tarn WY (2009) A role for transportin in deposition of TTP to cytoplasmic RNA granules and mRNA decay. Nucleic Acids Res 37:6600-6612. doi:10.1093/nar/gkp717

18. Chatterjee M, Paschal BM (2015) Disruption of the ran system by cysteine oxidation of the nucleotide exchange factor RCC1. Mol Cell Biol 35:566-581. doi:10.1128/MCB.01133-14

19. Collins M, Riascos D, Kovalik T, An JY, Krupa K, Krupa K et al (2012) The RNA-binding motif 45 (RBM45) protein accumulates in inclusion bodies in amyotrophic lateral sclerosis (ALS) and frontotemporal lobar degeneration with TDP-43 inclusions (FTLD-TDP) patients. Acta Neuropathol 124:717732. doi:10.1007/s00401-012-1045-x

20. Cooper-Knock J, Walsh MJ, Higginbottom A, Robin Highley J, Dickman MJ, Edbauer D et al (2014) Sequestration of multiple RNA recognition motif-containing proteins by $\mathrm{C} 9$ orf72 repeat expansions. Brain 137:2040-2051. doi:10.1093/brain/awu120

21. Couthouis J, Hart MP, Erion R, King OD, Diaz Z, Nakaya T et al (2012) Evaluating the role of the FUS/TLS-related gene EWSR1 in amyotrophic lateral sclerosis. Hum Mol Genet 21:2899-2911. doi:10.1093/Hmg/Dds116

22. Couthouis J, Hart MP, Shorter J, DeJesus-Hernandez M, Erion $\mathrm{R}$, Oristano R et al (2011) A yeast functional screen predicts new candidate ALS disease genes. P Natl Acad Sci USA 108:20881-20890. doi:10.1073/pnas.1109434108

23. D'Angelo MA, Raices M, Panowski SH, Hetzer MW (2009) Age-dependent deterioration of nuclear pore complexes causes a loss of nuclear integrity in postmitotic cells. Cell 136:284295. doi:10.1016/j.cell.2008.11.037

24. Deivasigamani S, Verma HK, Ueda R, Ratnaparkhi A, Ratnaparkhi GS (2014) A genetic screen identifies Tor as an interactor of VAPB in a Drosophila model of amyotrophic lateral sclerosis. Biol Open 3:1127-1138. doi:10.1242/bio.201410066

25. DeJesus-Hernandez M, Mackenzie IR, Boeve BF, Boxer AL, Baker M, Rutherford NJ et al (2011) Expanded GGGGCC hexanucleotide repeat in noncoding region of C9ORF72 causes chromosome 9p-linked FTD and ALS. Neuron 72:245-256. doi:10.1016/j.neuron.2011.09.011

26. Dormann D, Haass C (2011) TDP-43 and FUS: a nuclear affair. Trends Neurosci 34:339-348. doi:10.1016/j.tins.2011.05.002

27. Dormann D, Madl T, Valori CF, Bentmann E, Tahirovic S, Abou-Ajram C et al (2012) Arginine methylation next to the PY-NLS modulates transportin binding and nuclear import of FUS. EMBO J 31:4258-4275. doi:10.1038/emboj.2012.261 
28. Dormann D, Rodde R, Edbauer D, Bentmann E, Fischer I, Hruscha A et al (2010) ALS-associated fused in sarcoma (FUS) mutations disrupt transportin-mediated nuclear import. EMBO J 29:2841-2857. doi:10.1038/emboj.2010.143

29. Elden AC, Kim HJ, Hart MP, Chen-Plotkin AS, Johnson BS, Fang XD et al (2010) Ataxin-2 intermediate-length polyglutamine expansions are associated with increased risk for ALS. Nature 466:U1069-U1077. doi:10.1038/Nature09320

30. Ellis JD, Barrios-Rodiles M, Colak R, Irimia M, Kim T, Calarco JA et al (2012) Tissue-specific alternative splicing remodels protein-protein interaction networks. Mol Cell 46:884-892. doi:10.1016/j.molcel.2012.05.037

31. Farg MA, Soo KY, Warraich ST, Sundaramoorthy V, Blair IP, Atkin JD (2013) Ataxin-2 interacts with FUS and intermediatelength polyglutamine expansions enhance FUS-related pathology in amyotrophic lateral sclerosis. Hum Mol Genet 22:717728. doi:10.1093/Hmg/Dds479

32. Freibaum BD, Lu YB, Lopez-Gonzalez R, Kim NC, Almeida $\mathrm{S}$, Lee KH et al (2015) GGGGCC repeat expansion in C9orf72 compromises nucleocytoplasmic transport. Nature 525:129. doi:10.1038/nature14974

33. Freischmidt A, Wieland T, Richter B, Ruf W, Schaeffer V, Muller K et al (2015) Haploinsufficiency of TBK1 causes familial ALS and fronto-temporal dementia. Nat Neurosci 18:631. doi: $10.1038 / \mathrm{nn} .4000$

34. Fujimura K, Suzuki T, Yasuda Y, Murata M, Katahira J, Yoneda Y (2010) Identification of importin alpha1 as a novel constituent of RNA stress granules. Biochim Biophys Acta 1803:865871. doi:10.1016/j.bbamcr.2010.03.020

35. Fujita K, Ito H, Nakano S, Kinoshita Y, Wate R, Kusaka H (2008) Immunohistochemical identification of messenger RNA-related proteins in basophilic inclusions of adult-onset atypical motor neuron disease. Acta Neuropathol 116:439-445. doi:10.1007/s00401-008-0415-x

36. Gitcho MA, Bigio EH, Mishra M, Johnson N, Weintraub S, Mesulam M et al (2009) TARDBP 3'-UTR variant in autopsyconfirmed frontotemporal lobar degeneration with TDP-43 proteinopathy. Acta Neuropathol 118:633-645. doi:10.1007/ s00401-009-0571-7

37. Gitler AD, Tsuiji H (2016) There has been an awakening: emerging mechanisms of C9orf72 mutations in FTD/ALS. Brain Res. doi:10.1016/j.brainres.2016.04.004

38. Haeusler AR, Donnelly CJ, Periz G, Simko EAJ, Shaw PG, Kim MS et al (2014) C9orf72 nucleotide repeat structures initiate molecular cascades of disease. Nature 507:195. doi:10.1038/ Nature 13124

39. Hein MY, Hubner NC, Poser I, Cox J, Nagaraj N, Toyoda Y et al (2015) A human interactome in three quantitative dimensions organized by stoichiometries and abundances. Cell 163:712-723. doi:10.1016/j.cell.2015.09.053

40. Hill R, Cautain B, de Pedro N, Link W (2014) Targeting nucleocytoplasmic transport in cancer therapy. Oncotarget 5:11-28. doi:10.18632/oncotarget.1457

41. Hishikawa N, Niwa J, Doyu M, Ito T, Ishigaki S, Hashizume $Y$ et al (2003) Dorfin localizes to the ubiquitylated inclusions in Parkinson's disease, dementia with Lewy bodies, multiple system atrophy, and amyotrophic lateral sclerosis. Am J Pathol 163:609-619. doi:10.1016/S0002-9440(10)63688-7

42. Honda H, Hamasaki H, Wakamiya T, Koyama S, Suzuki SO, Fujii N et al (2015) Loss of hnRNPA1 in ALS spinal cord motor neurons with TDP-43-positive inclusions. Neuropathology 35:37-43. doi:10.1111/Neup.12153

43. Iguchi Y, Katsuno M, Niwa J, Takagi S, Ishigaki S, Ikenaka K et al (2013) Loss of TDP-43 causes age-dependent progressive motor neuron degeneration. Brain 136:1371-1382. doi:10.1093/ brain/awt029
44. Ishihara T, Ariizumi Y, Shiga A, Kato T, Tan CF, Sato T et al (2013) Decreased number of Gemini of coiled bodies and U12 snRNA level in amyotrophic lateral sclerosis. Hum Mol Genet 22:4136-4147. doi:10.1093/Hmg/Ddt262

45. Jackel S, Summerer AK, Thommes CM, Pan X, Voigt A, Schulz JB et al (2015) Nuclear import factor transportin and arginine methyltransferase 1 modify FUS neurotoxicity in Drosophila. Neurobiol Dis 74:76-88. doi:10.1016/j.nbd.2014.11.003

46. Jain S, Wheeler JR, Walters RW, Agrawal A, Barsic A, Parker R (2016) ATPase-modulated stress granules contain a diverse proteome and substructure. Cell 164:487-498. doi:10.1016/j. cell.2015.12.038

47. Johnson JO, Pioro EP, Boehringer A, Chia R, Feit H, Renton AE et al (2014) Mutations in the Matrin 3 gene cause familial amyotrophic lateral sclerosis. Nat Neurosci 17:664. doi: $10.1038 / \mathrm{Nn} .3688$

48. Jovicic A, Mertens J, Boeynaems S, Bogaert E, Chai N, Yamada SB et al (2015) Modifiers of C9orf72 dipeptide repeat toxicity connect nucleocytoplasmic transport defects to FTD/ALS. Nat Neurosci 18:1226. doi:10.1038/nn.4085

49. Kabashi E, Valdmanis PN, Dion P, Spiegelman D, McConkey BJ, Velde CV et al (2008) TARDBP mutations in individuals with sporadic and familial amyotrophic lateral sclerosis. Nat Genet 40:572-574. doi:10.1038/ng.132

50. Kaneb HM, Folkmann AW, Belzil VV, Jao LE, Leblond CS, Girard SL et al (2015) Deleterious mutations in the essential mRNA metabolism factor, hGle1, in amyotrophic lateral sclerosis. Hum Mol Genet 24:1363-1373. doi:10.1093/hmg/ddu545

51. Kato M, Han TNW, Xie SH, Shi K, Du XL, Wu LC et al (2012) Cell-free formation of RNA granules: low complexity sequence domains form dynamic fibers within hydrogels. Cell 149:753767. doi:10.1016/j.cell.2012.04.017

52. Keller BA, Volkening K, Droppelmann CA, Ang LC, Rademakers R, Strong MJ (2012) Co-aggregation of RNA binding proteins in ALS spinal motor neurons: evidence of a common pathogenic mechanism. Acta Neuropathol 124:733-747. doi:10.1007/s00401-012-1035-Z

53. Kim HJ, Kim NC, Wang YD, Scarborough EA, Moore J, Diaz $\mathrm{Z}$ et al (2013) Mutations in prion-like domains in hnRNPA2B1 and hnRNPA1 cause multisystem proteinopathy and ALS. Nature 495:467. doi:10.1038/Nature11922

54. Kim HJ, Raphael AR, LaDow ES, McGurk L, Weber RA, Trojanowski JQ et al (2014) Therapeutic modulation of eIF2 alpha phosphorylation rescues TDP-43 toxicity in amyotrophic lateral sclerosis disease models. Nat Genet 46:152. doi:10.1038/ Ng.2853

55. Kimura M, Kose S, Okumura N, Imai K, Furuta M, Sakiyama N et al (2013) Identification of cargo proteins specific for the nucleocytoplasmic transport carrier transportin by combination of an in vitro transport system and stable isotope labeling by amino acids in cell culture (SILAC)-based quantitative proteomics. Mol Cell Proteomics 12:145-157. doi:10.1074/mcp.M112.019414

56. Kimura M, Okumura N, Kose S, Takao T, Imamoto N (2013) Identification of cargo proteins specific for importin-beta with Importin-alpha applying a stable isotope labeling by amino acids in cell culture (SILAC)-based in vitro transport system. $\mathrm{J}$ Biol Chem 288:24540-24549. doi:10.1074/jbc.M113.489286

57. King OD, Gitler AD, Shorter J (2012) The tip of the iceberg: RNA-binding proteins with prion-like domains in neurodegenerative disease. Brain Res 1462:61-80. doi:10.1016/j. brainres.2012.01.016

58. Kinoshita $\mathrm{Y}$, Ito $\mathrm{H}$, Hirano A, Fujita K, Wate R, Nakamura M et al (2009) Nuclear contour irregularity and abnormal transporter protein distribution in anterior horn cells in amyotrophic lateral sclerosis. J Neuropathol Exp Neurol 68:1184-1192. doi:10.1097/NEN.0b013e3181bc3bec 
59. Kudo N, Taoka H, Toda T, Yoshida M, Horinouchi S (1999) A novel nuclear export signal sensitive to oxidative stress in the fission yeast transcription factor Pap1. J Biol Chem 274:1515115158. doi:10.1074/jbc.274.21.15151

60. Kwiatkowski TJ, Bosco DA, LeClerc AL, Tamrazian E, Vanderburg CR, Russ C et al (2009) Mutations in the FUS/TLS gene on chromosome 16 cause familial amyotrophic lateral sclerosis. Science 323:1205-1208. doi:10.1126/science.1166066

61. Kwon I, Xiang SH, Kato M, Wu L, Theodoropoulos P, Wang T et al (2014) Poly-dipeptides encoded by the C9orf72 repeats bind nucleoli, impede RNA biogenesis, and kill cells. Science 345:1139-1145. doi:10.1126/science. 1254917

62. Lagier-Tourenne C, Polymenidou M, Cleveland DW (2010) TDP-43 and FUS/TLS: emerging roles in RNA processing and neurodegeneration. Hum Mol Genet 19:R46-R64. doi:10.1093/ hmg/ddq137

63. Lagier-Tourenne C, Polymenidou M, Hutt KR, Vu AQ, Baughn M, Huelga SC et al (2012) Divergent roles of ALS-linked proteins FUS/TLS and TDP-43 intersect in processing long premRNAs. Nat Neurosci 15:1488-1497. doi:10.1038/nn.3230

64. Lee YB, Chen HJ, Peres JN, Gomez-Deza J, Attig J, Stalekar $\mathrm{M}$ et al (2013) Hexanucleotide repeats in ALS/FTD form length-dependent RNA foci, sequester RNA binding proteins, and are neurotoxic. Cell Reports 5:1178-1186. doi:10.1016/j. celrep.2013.10.049

65. Lepez-Otin C, Blasco MA, Partridge L, Serrano M, Kroemer G (2013) The hallmarks of aging. Cell 153:1194-1217. doi:10.1016/j.cell.2013.05.039

66. Liachko NF, McMillan PJ, Strovas TJ, Loomis E, Greenup L, Murrell JR et al (2014) The tau tubulin kinases TTBK1/2 promote accumulation of pathological TDP-43. PLoS Genet. doi:10.1371/journal.pgen.1004803

67. Licatalosi DD, Darnell RB (2006) Splicing regulation in neurologic disease. Neuron 52:93-101. doi:10.1016/j. neuron.2006.09.017

68. Ling SC, Polymenidou M, Cleveland DW (2013) Converging mechanisms in ALS and FTD: disrupted RNA and protein homeostasis. Neuron 79:416-438. doi:10.1016/j. neuron.2013.07.033

69. Liu-Yesucevitz L, Bassell GJ, Gitler AD, Hart AC, Klann E, Richter JD et al (2011) Local RNA translation at the synapse and in disease. J Neurosci 31:16086-16093. doi:10.1523/ Jneurosci.4105-11.2011

70. Liu-Yesucevitz L, Bilgutay A, Zhang YJ, Vanderwyde T, Citro A, Mehta $T$ et al (2010) Tar DNA binding protein-43 (TDP43) associates with stress granules: analysis of cultured cells and pathological brain tissue. PLoS One. doi:10.1371/journal. pone. 0013250

71. Maharjan N, Kunzli C, Buthey K, Saxena S (2016) C9ORF72 regulates stress granule formation and its deficiency impairs stress granule assembly, hypersensitizing cells to stress. Mol Neurobiol. doi:10.1007/s12035-016-9850-1

72. Mahboubi H, Seganathy E, Kong D, Stochaj U (2013) Identification of novel stress granule components that are involved in nuclear transport. PLoS One. doi:10.1371/journal. pone. 0068356

73. Manfredi G, Xu ZS (2005) Mitochondrial dysfunction and its role in motor neuron degeneration in ALS. Mitochondrion 5:77-87. doi:10.1016/j.mito.2005.01.002

74. May S, Hornburg D, Schludi MH, Arzberger T, Rentzsch K, Schwenk BM et al (2014) C9orf72 FTLD/ALS-associated Gly-Ala dipeptide repeat proteins cause neuronal toxicity and Unc119 sequestration. Acta Neuropathol 128:485-503. doi:10.1007/s00401-014-1329-4

75. McGurk L, Lee VM, Trojanowksi JQ, Van Deerlin VM, Lee EB, Bonini NM (2014) Poly-A binding protein-1 localization to a subset of TDP-43 inclusions in amyotrophic lateral sclerosis occurs more frequently in patients harboring an expansion in C9orf72. J Neuropathol Exp Neurol 73:837-845

76. Merkin J, Russell C, Chen P, Burge CB (2012) Evolutionary dynamics of gene and isoform regulation in mammalian tissues. Science 338:1593-1599. doi:10.1126/science.1228186

77. Milani P, Amadio M, Laforenza U, Dell'Orco M, Diamanti L, Sardone V et al (2013) Posttranscriptional regulation of SOD1 gene expression under oxidative stress: potential role of ELAV proteins in sporadic ALS. Neurobiol Dis 60:51-60. doi:10.1016/j.nbd.2013.08.005

78. Mizielinska S, Gronke S, Niccoli T, Ridler CE, Clayton EL, Devoy A et al (2014) C9orf72 repeat expansions cause neurodegeneration in Drosophila through arginine-rich proteins. Science 345:1192-1194. doi:10.1126/science. 1256800

79. Molliex A, Temirov J, Lee J, Coughlin M, Kanagaraj AP, Kim HJ et al (2015) Phase separation by low complexity domains promotes stress granule assembly and drives pathological fibrillization. Cell 163:123-133. doi:10.1016/j.cell.2015.09.015

80. Mori K, Arzberger T, Grasser FA, Gijselinck I, May S, Rentzsch $\mathrm{K}$ et al (2013) Bidirectional transcripts of the expanded C9orf72 hexanucleotide repeat are translated into aggregating dipeptide repeat proteins. Acta Neuropathol 126:881-893. doi:10.1007/ s00401-013-1189-3

81. Mori K, Lammich S, Mackenzie IRA, Forne I, Zilow S, Kretzschmar H et al (2013) hnRNP A3 binds to GGGGCC repeats and is a constituent of p62-positive/TDP43-negative inclusions in the hippocampus of patients with C9orf72 mutations. Acta Neuropathol 125:413-423. doi:10.1007/ s00401-013-1088-7

82. Mori K, Weng SM, Arzberger T, May S, Rentzsch K, Kremmer E et al (2013) The C9orf72 GGGGCC repeat is translated into aggregating dipeptide-repeat proteins in FTLD/ALS. Science 339:1335-1338. doi:10.1126/science.1232927

83. Murakami T, Qamar S, Lin JQ, Schierle GS, Rees E, Miyashita A et al (2015) ALS/FTD mutation-induced phase transition of FUS liquid droplets and reversible hydrogels into irreversible hydrogels impairs RNP granule function. Neuron 88:678-690. doi:10.1016/j.neuron.2015.10.030

84. Nagara Y, Tateishi T, Yamasaki R, Hayashi S, Kawamura M, Kikuchi $\mathrm{H}$ et al (2013) Impaired cytoplasmic-nuclear transport of hypoxia-inducible factor-1alpha in amyotrophic lateral sclerosis. Brain Pathol 23:534-546. doi:10.1111/bpa.12040

85. Neary D, Snowden J, Mann D (2005) Frontotemporal dementia. Lancet Neurol 4:771-780. doi:10.1016/ S1474-4422(05)70223-4

86. Neumann M (2009) Molecular neuropathology of TDP43 proteinopathies. Int J Mol Sci 10:232-246. doi:10.3390/ Ijms 10010232

87. Neumann M, Bentmann E, Dormann D, Jawaid A, DeJesusHernandez M, Ansorge $\mathrm{O}$ et al (2011) FET proteins TAF15 and EWS are selective markers that distinguish FTLD with FUS pathology from amyotrophic lateral sclerosis with FUS mutations. Brain 134:2595-2609. doi:10.1093/Brain/Awr201

88. Neumann M, Igaz LM, Kwong LK, Nakashima-Yasuda H, Kolb SJ, Dreyfuss G et al (2007) Absence of heterogeneous nuclear ribonucleoproteins and survival motor neuron protein in TDP-43 positive inclusions in frontotemporal lobar degeneration. Acta Neuropathol 113:543-548. doi:10.1007/ s00401-007-0221-x

89. Neumann M, Rademakers R, Roeber S, Baker M, Kretzschmar HA, Mackenzie IRA (2009) A new subtype of frontotemporal lobar degeneration with FUS pathology. Brain 132:2922-2931. doi:10.1093/brain/awp214

90. Neumann M, Sampathu DM, Kwong LK, Truax AC, Micsenyi MC, Chou TT et al (2006) Ubiquitinated TDP-43 in 
frontotemporal lobar degeneration and amyotrophic lateral sclerosis. Science 314:130-133. doi:10.1126/science.1134108

91. Neumann M, Valori CF, Ansorge O, Kretzschmar HA, Munoz DG, Kusaka $\mathrm{H}$ et al (2012) Transportin 1 accumulates specifically with FET proteins but no other transportin cargos in FTLD-FUS and is absent in FUS inclusions in ALS with FUS mutations. Acta Neuropathol 124:705-716. doi:10.1007/ s00401-012-1020-6

92. Nishimura AL, Zupunski V, Troakes C, Kathe C, Fratta P, Howell $\mathrm{M}$ et al (2010) Nuclear import impairment causes cytoplasmic trans-activation response DNA-binding protein accumulation and is associated with frontotemporal lobar degeneration. Brain 133:1763-1771. doi:10.1093/brain/awq111

93. Padhi AK, Jayaram B, Gomes J (2013) Prediction of functional loss of human angiogenin mutants associated with ALS by molecular dynamics simulations. Sci Rep UK. doi:10.1038/ Srep01225

94. Patel A, Lee HO, Jawerth L, Maharana S, Jahnel M, Hein MY et al (2015) A liquid-to-solid phase transition of the ALS protein FUS accelerated by disease mutation. Cell 162:1066-1077. doi:10.1016/j.cell.2015.07.047

95. Perry RB, Doron-Mandel E, Iavnilovitch E, Rishal I, Dagan SY, Tsoory M et al (2012) Subcellular knockout of Importin beta 1 perturbs axonal retrograde signaling. Neuron 75:294-305. doi:10.1016/j.neuron.2012.05.033

96. Porta S, Kwong LK, Trojanowski JQ, Lee VMY (2015) Drosha inclusions are new components of dipeptide-repeat protein aggregates in FTLD-TDP and ALS C9orf72 expansion cases. J Neuropathol Exp Neurol 74:380-387

97. Raj B, Blencowe BJ (2015) Alternative splicing in the mammalian nervous system: recent insights into mechanisms and functional roles. Neuron 87:14-27. doi:10.1016/j. neuron.2015.05.004

98. Ramaswami M, Taylor JP, Parker R (2013) Altered ribostasis: RNA-protein granules in degenerative disorders. Cell 154:727736. doi:10.1016/j.cell.2013.07.038

99. Renton AE, Chio A, Traynor BJ (2014) State of play in amyotrophic lateral sclerosis genetics. Nat Neurosci 17:17-23. doi:10.1038/nn.3584

100. Renton AE, Majounie E, Waite A, Simon-Sanchez J, Rollinson S, Gibbs JR et al (2011) A hexanucleotide repeat expansion in C9ORF72 is the cause of chromosome 9p21-linked ALS-FTD. Neuron 72:257-268. doi:10.1016/j.neuron.2011.09.010

101. Ross CA, Poirier MA (2004) Protein aggregation and neurodegenerative disease. Nat Med 10:S10-S17. doi:10.1038/nm1066

102. Rossi S, Cozzolino M, Teresa Carri M (2016) Old versus new mechanisms in the pathogenesis of ALS. Brain Pathol. doi:10.1111/bpa.12355

103. Savas JN, Toyama BH, Xu T, Yates JR, Hetzer MW (2012) Extremely long-lived nuclear pore proteins in the rat brain. Science 335:942. doi:10.1126/science.1217421

104. Saxena S, Caroni P (2011) Selective neuronal vulnerability in neurodegenerative diseases: from stressor thresholds to degeneration. Neuron 71:35-48. doi:10.1016/j.neuron.2011.06.031

105. Sellier C, Campanari ML, Julie Corbier C, Gaucherot A, KolbCheynel I, Oulad-Abdelghani M et al (2016) Loss of C9ORF72 impairs autophagy and synergizes with polyQ Ataxin-2 to induce motor neuron dysfunction and cell death. EMBO J. doi:10.15252/embj.201593350

106. Sephton CF, Cenik C, Kucukural A, Dammer EB, Cenik B, Han YH et al (2011) Identification of neuronal RNA targets of TDP-43-containing ribonucleoprotein complexes. J Biol Chem 286:1204-1215. doi:10.1074/jbc.M110.190884

107. Seyfried NT, Gozal YM, Dammer EB, Xia QW, Duong DM, Cheng DM et al (2010) Multiplex SILAC analysis of a cellular TDP-43 proteinopathy model reveals protein inclusions associated with SUMOylation and diverse polyubiquitin chains. Mol Cell Proteomics 9:705-718. doi:10.1074/mcp. M800390-MCP200

108. Shelkovnikova TA, Robinson HK, Troakes C, Ninkina N, Buchman VL (2014) Compromised paraspeckle formation as a pathogenic factor in FUSopathies. Hum Mol Genet 23:2298-2312. doi:10.1093/hmg/ddt622

109. Sieben A, Van Langenhove T, Engelborghs S, Martin JJ, Boon P, Cras P et al (2012) The genetics and neuropathology of frontotemporal lobar degeneration. Acta Neuropathol 124:353-372. doi:10.1007/s00401-012-1029-x

110. Smith BN, Ticozzi N, Fallini C, Gkazi AS, Topp S, Kenna $\mathrm{KP}$ et al (2014) Exome-wide rare variant analysis identifies TUBA4A mutations associated with familial ALS. Neuron 84:324-331. doi:10.1016/j.neuron.2014.09.027

111. Sreedharan J, Blair IP, Tripathi VB, Hu X, Vance C, Rogelj B et al (2008) TDP-43 mutations in familial and sporadic amyotrophic lateral sclerosis. Science 319:1668-1672. doi:10.1126/ science. 1154584

112. Stalekar M, Yin X, Rebolj K, Darovic S, Troakes C, Mayr M et al (2015) Proteomic analyses reveal that Loss of Tdp-43 affects Rna processing and intracellular transport. Neuroscience 293:157-170. doi:10.1016/j.neuroscience.2015.02.046

113. Sun ZH, Diaz Z, Fang XD, Hart MP, Chesi A, Shorter J et al (2011) Molecular determinants and genetic modifiers of aggregation and toxicity for the ALS disease protein FUS/TLS. PLoS Biol. doi:10.1371/journal.pbio.1000614

114. Swinnen B, Robberecht W (2014) The phenotypic variability of amyotrophic lateral sclerosis. Nat Rev Neurol 10:661-670. doi:10.1038/nrneurol.2014.184

115. Tao Z, Wang H, Xia Q, Li K, Jiang X, Xu G et al (2015) Nucleolar stress and impaired stress granule formation contribute to C9orf72 RAN translation-induced cytotoxicity. Hum Mol Genet 24:2426-2441. doi:10.1093/hmg/ddv005

116. Tateno M, Kato S, Sakurai T, Nukina N, Takahashi R, Araki $\mathrm{T}$ (2009) Mutant SOD1 impairs axonal transport of choline acetyltransferase and acetylcholine release by sequestering KAP3. Hum Mol Genet 18:942-955. doi:10.1093/hmg/ddn422

117. Tauffenberger A, Chitramuthu BP, Bateman A, Bennett HP, Parker JA (2013) Reduction of polyglutamine toxicity by TDP43, FUS and progranulin in Huntington's disease models. Hum Mol Genet 22:782-794. doi:10.1093/hmg/dds485

118. Taylor JP (2015) Multisystem proteinopathy intersecting genetics in muscle, bone, and brain degeneration. Neurology 85:658660. doi:10.1212/Wnl.0000000000001862

119. Thakar K, Karaca S, Port SA, Urlaub H, Kehlenbach RH (2013) Identification of CRM1-dependent nuclear export cargos using quantitative mass spectrometry. Mol Cell Proteomics 12:664678. doi:10.1074/mcp.M112.024877

120. Tran D, Chalhoub A, Schooley A, Zhang W, Ngsee JK (2012) A mutation in VAPB that causes amyotrophic lateral sclerosis also causes a nuclear envelope defect. J Cell Sci 125:2831-2836. doi: $10.1242 /$ jcs. 102111

121. Tran H, Almeida S, Moore J, Gendron TF, Chalasani U, Lu $Y$ et al (2015) Differential toxicity of nuclear RNA foci versus dipeptide repeat proteins in a Drosophila model of C9ORF72 FTD/ALS. Neuron 87:1207-1214. doi:10.1016/j. neuron.2015.09.015

122. Tsuiji H, Iguchi Y, Furuya A, Kataoka A, Hatsuta H, Atsuta $\mathrm{N}$ et al (2013) Spliceosome integrity is defective in the motor neuron diseases ALS and SMA. Embo Mol Med 5:221-234. doi:10.1002/emmm.201202303

123. Vance C, Rogelj B, Hortobagyi T, De Vos KJ, Nishimura AL, Sreedharan J et al (2009) Mutations in FUS, an RNA processing protein, cause familial amyotrophic lateral sclerosis type 6 . Science 323:1208-1211. doi:10.1126/science.1165942 
124. Vanderweyde T, Yu H, Varnum M, Liu-Yesucevitz L, Citro A, Ikezu T et al (2012) Contrasting pathology of the stress granule proteins TIA-1 and G3BP in tauopathies. J Neurosci 32:82708283. doi:10.1523/Jneurosci.1592-12.2012

125. Volkening K, Leystra-Lantz C, Yang WC, Jaffee H, Strong MJ (2009) Tar DNA binding protein of $43 \mathrm{kDa}$ (TDP-43), 14-3-3 proteins and copper/zinc superoxide dismutase (SOD1) interact to modulate NFL mRNA stability. Implications for altered RNA processing in amyotrophic lateral sclerosis (ALS). Brain Res 1305:168-182. doi:10.1016/j.brainres.2009.09.105

126. Ward ME, Taubes A, Chen R, Miller BL, Sephton CF, Gelfand JM et al (2014) Early retinal neurodegeneration and impaired Ran-mediated nuclear import of TDP-43 in progranulin-deficient FTLD. J Exp Med 211:1937-1945. doi:10.1084/ jem.20140214

127. Warde-Farley D, Donaldson SL, Comes O, Zuberi K, Badrawi R, Chao P et al (2010) The GeneMANIA prediction server: biological network integration for gene prioritization and predicting gene function. Nucleic Acids Res 38:W214-W220. doi:10.1093/nar/gkq537

128. Watanabe M, Dykes-Hoberg M, Culotta VC, Price DL, Wong PC, Rothstein JD (2001) Histological evidence of protein aggregation in mutant SOD1 transgenic mice and in amyotrophic lateral sclerosis neural tissues. Neurobiol Dis 8:933941. doi:10.1006/nbdi.2001.0443

129. Wen XM, Tan WZ, Westergard T, Krishnamurthy K, Markandaiah SS, Shi YX et al (2014) Antisense proline-arginine RAN dipeptides linked to C9ORF72-ALS/FTD form toxic nuclear aggregates that initiate in vitro and in vivo neuronal death. Neuron 84:1213-1225. doi:10.1016/j.neuron.2014.12.010

130. Woerner AC, Frottin F, Hornburg D, Feng LR, Meissner F, Patra $\mathrm{M}$ et al (2016) Cytoplasmic protein aggregates interfere with nucleocytoplasmic transport of protein and RNA. Science 351:173-176. doi:10.1126/science.aad2033

131. Wong NKY, He BP, Strong MJ (2000) Characterization of neuronal intermediate filament protein expression in cervical spinal motor neurons in sporadic amyotrophic lateral sclerosis (ALS). J Neuropath Exp Neur 59:972-982

132. Xiang SH, Kato M, Wu LC, Lin Y, Ding M, Zhang YJ et al (2015) The LC domain of hnRNPA2 adopts similar conformations in hydrogel polymers, liquid-like droplets, and nuclei. Cell 163:829-839. doi:10.1016/j.cell.2015.10.040

133. Xiao S, MacNair L, McGoldrick P, McKeever PM, McLean JR, Zhang $\mathrm{M}$ et al (2015) Isoform-specific antibodies reveal distinct subcellular localizations of C9orf72 in amyotrophic lateral sclerosis. Ann Neurol 78:568-583. doi:10.1002/ana.24469

134. Xiao SX, McLean J, Robertson J (2006) Neuronal intermediate filaments and ALS: a new look at an old question. BBA Mol Basis Dis 1762:1001-1012. doi:10.1016/j.bbadis.2006.09.003

135. Xiao SX, Sanelli T, Chiang HL, Sun YL, Chakrabartty A, Keith $\mathrm{J}$ et al (2015) Low molecular weight species of TDP-43 generated by abnormal splicing form inclusions in amyotrophic lateral sclerosis and result in motor neuron death. Acta Neuropathol 130:49-61. doi:10.1007/s00401-015-1412-5
136. Yang CX, Wang HY, Qiao T, Yang B, Aliaga L, Qiu LH et al (2014) Partial loss of TDP-43 function causes phenotypes of amyotrophic lateral sclerosis. Proc Natl Acad Sci USA 111:E1121-E1129. doi:10.1073/pnas.1322641111

137. Yang WC, Sopper MM, Leystra-Lantz C, Strong MJ (2003) Microtubule-associated tau protein positive neuronal and glial inclusions in ALS. Neurology 61:1766-1773

138. Yang XX, Shen Y, Garre E, Hao XX, Krumlinde D, Cvijovic $M$ et al (2014) Stress granule-defective mutants deregulate stress responsive transcripts. PLoS Genet. doi:10.1371/journal. pgen.1004763

139. Yeo G, Holste D, Kreiman G, Burge CB (2004) Variation in alternative splicing across human tissues. Genome Biol. doi:10.1186/Gb-2004-5-10-R74

140. Yoshimura SH, Otsuka S, Kumeta M, Taga M, Takeyasu K (2013) Intermolecular disulfide bonds between nucleoporins regulate karyopherin-dependent nuclear transport. J Cell Sci 126:3141. doi:10.1242/jcs. 124172

141. Yudin D, Hanz S, Yoo S, Iavnilovitch E, Willis D, Gradus T (2008) Localized regulation of axonal RanGTPase controls retrograde injury signaling in peripheral nerve. Neuron 59:241252. doi:10.1016/j.neuron.2008.05.029

142. Zhan LH, Hanson KA, Kim SH, Tare A, Tibbetts RS (2013) Identification of genetic modifiers of TDP-43 neurotoxicity in Drosophila. PLoS One. doi:10.1371/journal.pone.0057214

143. Zhang JH, Ito $\mathrm{H}$, Wate R, Ohnishi S, Nakano S, Kusaka H (2006) Altered distributions of nucleocytoplasmic transportrelated proteins in the spinal cord of a mouse model of amyotrophic lateral sclerosis. Acta Neuropathol 112:673-680. doi:10.1007/s00401-006-0130-4

144. Zhang K, Donnelly CJ, Haeusler AR, Grima JC, Machamer JB, Steinwald P et al (2015) The C9orf72 repeat expansion disrupts nucleocytoplasmic transport. Nature 525:56. doi:10.1038/ nature 14973

145. Zhang YJ, Gendron TF, Grima JC, Sasaguri H, Jansen-West K, $\mathrm{Xu}$ YF et al (2016) C9ORF72 poly(GA) aggregates sequester and impair HR23 and nucleocytoplasmic transport proteins. Nat Neurosci. doi:10.1038/nn.4272

146. Zhang YJ, Xu YF, Cook C, Gendron TF, Roettges P, Link CD et al (2009) Aberrant cleavage of TDP-43 enhances aggregation and cellular toxicity. Proc Natl Acad Sci USA 106:7607-7612. doi:10.1073/pnas.0900688106

147. Zhou YQ, Liu SY, Liu GD, Ozturk A, Hicks GG (2013) ALSassociated FUS mutations result in compromised FUS alternative splicing and autoregulation. PLoS Genet. doi:10.1371/journal.pgen.1003895

148. Zu T, Liu YJ, Baez-Coronel M, Reid T, Pletnikova O, Lewis $\mathrm{J}$ et al (2013) RAN proteins and RNA foci from antisense transcripts in C9ORF72 ALS and frontotemporal dementia. P Natl Acad Sci USA 110:E4968-E4977. doi:10.1073/ pnas. 1315438110 